\title{
MicroRNA-126 induces autophagy by altering cell metabolism in malignant mesothelioma
}

\author{
Marco Tomasetti ${ }^{1}$, Federica Monaco ${ }^{1}$, Nicola Manzella ${ }^{1}$, Jakub Rohlena ${ }^{2}$, Katerina \\ Rohlenova ${ }^{2}$, Sara Staffolani ${ }^{1}$, Simona Gaetani ${ }^{1}$, Veronica Ciarapica ${ }^{1}$, Monica Amati ${ }^{1}$, \\ Massimo Bracci ${ }^{1}$, Matteo Valentino ${ }^{1}$, Jacob Goodwin ${ }^{3}$, Maria Nguyen ${ }^{3}$, Jaroslav \\ Truksa ${ }^{2}$, Margaryta Sobol ${ }^{4}$, Pavel Hozak ${ }^{4}$, Lan-Feng Dong ${ }^{3}$, Lory Santarelli ${ }^{1}$, Jiri \\ Neuzil ${ }^{2,3}$ \\ ${ }^{1}$ Department of Clinical and Molecular Science, Polytechnic University of Marche, 60020, Ancona, Italy \\ ${ }^{2}$ Institute of Biotechnology, Czech Academy of Sciences, BIOCEV, Vestec-Prague West, 25242, Czech Republic \\ ${ }^{3}$ School of Medical Science and Griffith Health Institute, Griffith University, Southport, Qld, 4222, Australia \\ ${ }^{4}$ Institute of Molecular Genetics, Czech Academy of Sciences, Prague 4, 142 20, Czech Republic \\ Correspondence to: Marco Tomasetti, e-mail: m.tomasetti@univpm.it \\ Jiri Neuzil, e-mail: j.neuzil@griffith.edu.au \\ Keywords: MIR 126, malignant mesothelioma, autophagy, cell metabolism, tumor suppression \\ Received: October 23, $2015 \quad$ Accepted: March 28, $2016 \quad$ Published: April 22, 2016
}

\section{ABSTRACT}

Autophagy favors both cell survival and cancer suppression, and increasing evidence reveals that microRNAs (MIRs) regulate autophagy. Previously we reported that MIR126 is downregulated in malignant mesothelioma (MM). Therefore, we investigated the role of MIR126 in the regulation of cell metabolism and autophagy in MM models. We report that MIR126 induces autophagic flux in MM cells by downregulating insulin receptor substrate-1 (IRS1) and disrupting the IRS1 signaling pathway. This was specific to MM cells, and was not observed in non-malignant cells of mesothelial origin or in MM cells expressing MIR126-insensitive IRS1 transcript. The MIR126 effect on autophagy in MM cells was recapitulated by IRS1 silencing, and antagonized by IRS1 overexpression or antisense MIR126 treatment. The MIR126induced loss of IRS1 suppressed glucose uptake, leading to energy deprivation and AMPK-dependent phosphorylation of ULK1. In addition, MIR126 stimulated lipid droplet accumulation in a hypoxia-inducible factor-1a (HIF1a)-dependent manner. MIR126 also reduced pyruvate dehydrogenase kinase (PDK) and acetyl-CoA-citrate lyase (ACL) expression, leading to the accumulation of cytosolic citrate and paradoxical inhibition of pyruvate dehydrogenase (PDH) activity. Simultaneous pharmacological and genetic intervention with PDK and ACL activity phenocopied the effects of MIR126. This suggests that in MM MIR126 initiates a metabolic program leading to high autophagic flux and HIF1a stabilization, incompatible with tumor progression of MM. Consistently, MIR126-expressing MM cells injected into immunocompromised mice failed to progress beyond the initial stage of tumor formation, showing that increased autophagy has a protective role in MM.

\section{INTRODUCTION}

Metabolic reprogramming of cancer cells is essential for their adaptation to tumor microenvironment and for maintenance of tumor growth [1]. Autophagy is a catabolic pathway that has a fundamental role in this adaptation [2]. Depending on the context, autophagy can induce cell death or promote tumor inhibition [3]. Malignant transformation is frequently associated with suppression of autophagy. Recent implication of tumor suppressors like beclin-1 (BECN1) in autophagic pathways indicates a causative role for autophagy deficiencies in cancer formation. It has been documented that autophagy is strictly controlled to maintain homeostatic balance of energy metabolism 
and turnover of proteins as well as cellular organelles $[4,5]$. This process is post-transcriptionally regulated by small non-coding microRNAs $(M I R s)$ that regulate gene expression via complementary base-pairing with mRNAs [6].

Among various $M I R s, M I R 126$ has an important role in cancer biology, since it can inhibit progression of certain cancers via negative control of proliferation, migration, invasion and cell survival $[7,8]$. In tumour cells, MIR126 alters a number of cellular functions via suppressing translation of different target genes [9]. Anti-proliferative effect of MIR126 was found in several tumour types including colon cancer, non-small cell lung cancer and malignant mesothelioma (MM) via targeting different members of the PI3K/AKT pathway [10-12]. Similarly, MIR126 was found to suppress tumours by directly targeting the insulin receptor substrate-1 (IRS1) [12-14] and the disintegrin- and metalloproteinase domaincontaining protein-9 (ADAM9) [15]. Using luciferase assay, it was found that MIR126 targets other factors, such as SOX2, SLC7A5, EGFL7 and VEGF [16-20].

Here, we report that MIR126 acts as an inducer of autophagic flux in MM. Ectopic overexpression of MIR126 increased autophagic activity by altering the insulin signaling pathway through IRS1, resulting in reduced glucose uptake. Under low glucose conditions, MM cells activated the AMPK/mTOR signaling pathway as an energy-dependent regulator of autophagy. We also show that MIR126 overexpression was accompanied by accumulation of intracellular lipid droplets (LDs) in MM cells due to alteration of mitochondrial function in a hypoxia-inducible factor-1 $\alpha$ (HIF $1 \alpha)$-dependent manner.

\section{RESULTS}

\section{Overexpression of MIR126 induces autophagic flux}

To explore the role of MIR126 in autophagy, MM cells (cell line H28) and non-malignant mesothelial cells (cell line Met5A) transfected with MIR126 and empty plasmid were stained with acridine orange (AO) or transfected with mCHERRY-EGFP-LC3B plasmid. Punctuate acid vesicle (AV) formation (AO staining) was evaluated by fluorescence microscope. As shown in Figure 1A, there was a marked increase of AVs in MIRtransfected MM cells compared to MM cells carrying an empty plasmid, which was reversed by blocking the function of MIR126 using anti-MIR126 (Supplementary Figure S1A upper panels). The AVs were perinuclear and overlayed with mitochondria suggesting a possible increase in autophagic/mitophagic flux in MIR126expressing cells. In contrast, no effect on AV formation was found upon MIR126 introduction into non-malignant Met5A cells. To directly assess the effect of MIR126 on the autophagic flux, we transfected the MIR126-expressing and mock cells with a mCHERRY-EGFP-LC3B fusion construct. The LC3B-fused EGFP loses fluorescence due to the acidic environment of lysosomes, while mCHERRY retains it, discriminating between autophagosomes in the cytoplasm (visualized as yellow/green punctae) and those in the lysosome (visualized as red punctae). As shown in Figure $1 \mathrm{~B}$ the ratio of red to green punctae was increased in MIR126-expressing malignant $\mathrm{H} 28$ cells indicating accelerated lysosomal delivery of autophagosomes and increased autophagic flux, but it remained unaffected by MIR126 in non-malignant Met5A cells. This suggests that MIR126 increases autophagic flux in MM cells.

Next, we assessed markers of autophagy including BECN1, SQSTM1 and the conversion of LC3I (cytosolic form) to LC3II (lipidated, autophagosome membranebound form) by western blotting (WB). MIR126 overexpression led to significant upregulation of SQSTM1 in MM cells, while BECN1 did not show significant changes (Figure 1C). In cancer cells, MIR126 induced reduction of LC3II levels rather than its accumulation, consistent with increased lysosomal delivery of the autophagosome-incorporated LC3II indicated by the dual fluorescence construct described above. To further determine whether MIR126 induces autophagy flux or blocks autophagy initiation (this could also reduce the LC3II levels), we investigated LC3 turnover in the presence of autophagy inhibitors. Cells were treated with 3-methyladenine (3MA) or chloroquine (CQ) to block autophagosome formation, or autophagic degradation (autophagosome-lysosome fusion), respectively. CQ treatment caused significant increase of LC3II protein in MIR126-transfected MM cells, suggesting that the overexpression of MIR 126 indeed induces the autophagic flux. A slight effect in empty plasmid-transfected cells was also observed, indicating basal autophagic activity (Figure 1D). Inhibition of upstream steps of autophagy by 3MA also induced LC3II accumulation in MM cells. 3MA is widely used as autophagy inhibitor based on its inhibitory effect on class III PI3K activity. However, 3MA was found to promote autophagic flux under certain conditions [21]. It was reported that $3 \mathrm{MA}$ can induce autophagy similarly as rapamycin, via suppression of mTOR function [22]. It is therefore likely that LC3II accumulation in this situation is the result of 3MA-induced autophagy. Collectively, these results indicate that MIR126 expression upregulates autophagic flux in MM cells but not in their non-malignant counterparts.

\section{Insulin receptor substrate-1 (IRS1), a target of MIR126, is involved in autophagic activity}

IRS1 is the functional downstream target of MIR126 via its 3'UTR [12-14]. IRS1, activated from the insulin-like growth factor-1 (IGF1) receptor, recruits intracellular proteins to transduce incoming signals in a cascade-like manner, leading to activation of the PI3K/ 

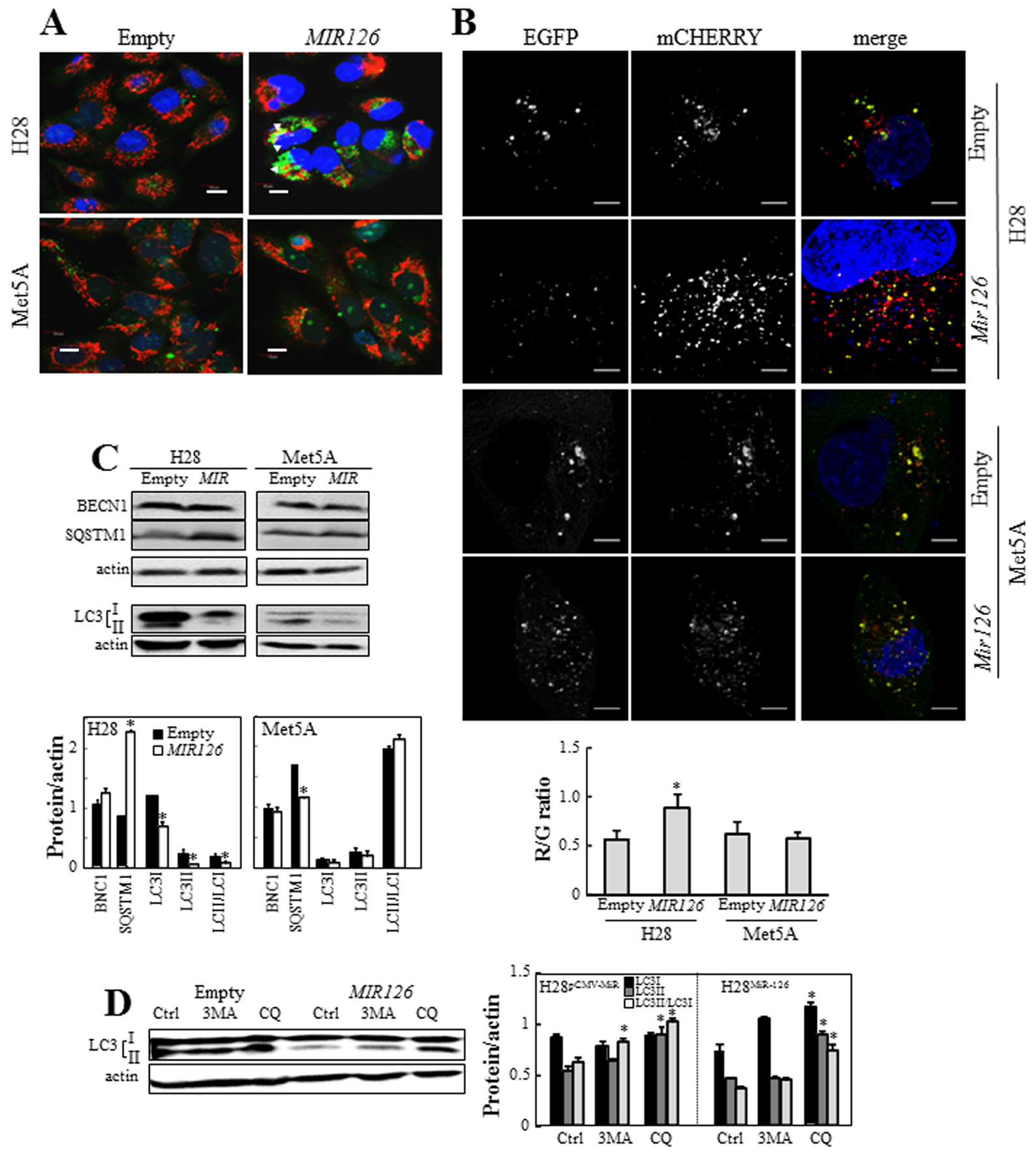

Figure 1: Ectopic MIR126 induces autophagic flux. A. MIR126-transfected H28 and Met5A cells and their empty plasmid-transfected counterparts were stained with AO and TMRM, and AVs (green) and mitochondria (red) visualized by fluorescent microscopy. The yellow spots indicate overlaying AVs and mitochondria. Scale bars represent $10 \mu \mathrm{m}$. B. MIR126-transfected H28 and Met5A cells and their empty plasmid-transfected counterparts were transiently transfected with dual fluorescence mCHERRY-EGFP-LC3B vector, and the red (R, lysosomal autophagosomes), green (G, autophagosomes) were visualized. Typical cells are shown, scale bars represent $5 \mu \mathrm{m}$. Evaluation of the ratio of red/green dots in empty plasmid- and MIR126-transfected H28 and Met5A cells. The number of cells evaluated in each condition was n=56 for $\mathrm{H} 28$ and 32 for Met5A, from 5 independent experiments. The symbol "*” indicates significant difference between mock and MIR126 cells. Error bars indicate S.E.M. C. Expression of autophagic markers BECN1, SQSTM1, and LC3I/II. Densitometric evaluation of the bands shown in D related to the level of actin (lower panel). D. Overexpression of MIR126 induces autophagic flux. MIR126-transfected Met5A and H28 cells and their empty plasmid-transfected counterparts were incubated in the presence and absence of 3MA or CQ for $24 \mathrm{~h}$, and evaluated for LC3 conversion. Densitometric analysis of LC3 conversion related to actin (lower panel). The data shown are mean values \pm S.D. derived from three independent experiments. Comparisons among groups were determined by one-way ANOVA with Tukey post-hoc analysis; the symbol "**" denotes significant differences compared with empty plasmid-transfected cells, or controls (Ctrl) versus treatments (3MA and CQ), with $\mathrm{p}<0.05$. 
mTOR signaling, negatively regulating autophagy. To evaluate the role of IRS1 in MIR126-induced autophagy, IRS1 was overexpressed or silenced in MIR- and empty vector-transfected MM cells, and AV formation and LC3 conversion were evaluated. As previously reported, MIR126 downregulates IRS1 [12], which is associated with increased AV formation and reduced level of LC3II/ LC3I ratio as a result of increased autophagic activity. Overexpression of IRS1 inhibited AV formation and induced LC3II accumulation in MIR126 transfected cells. Conversely, IRS1 silencing induced AV formation and reduced LC3II level in both MIR126- and empty plasmid-transfected MM cells, thus resembling MIR126 overexpression (Supplementary Figure 2). Additionally, we used IstMes2 cells with truncated IRS1 lacking its MIR126 binding site (see the sequence in Figure S2) to address whether this finding also applies to unchanged IRS1 level. IstMes 2 cells carrying truncated IRS1 were not sensitive to MiR126-induced autophagy (Supplementary Figure S3A, S3B). Inhibition of autophagy by $3 \mathrm{MA}$ or CQ did not induce further LC3II accumulation in MIR126- and empty plasmid-transfected IstMes2 cells, supporting the premise that these cells lack autophagic activity (Figure S3C). Conversely, suppression of IRS1 by siRNA induced $\mathrm{AV}$ formation and LCII turnover as a result of increased autophagic flux (Figure S3D, S3E).

\section{MIR126 affects glucose uptake}

MIR126 may affect the insulin pathway signaling by targeting IRS1. We therefore asked whether MIR 126 alters glucose homeostasis in the context of altered autophagic response. The glucose transporter-4 (GLUT-4) is the main glucose carrier responsible for insulin-regulated glucose uptake [23]. As shown in Figure 3A, 3B, ectopic MIR126 increased GLUT-4 expression in Met5A cells and, to a larger extent, in malignant $\mathrm{H} 28$ cells. On the other hand, decreased GLUT-4 levels were found in MIR126non-responsive IstMes2 cells. Even though GLUT-4 was highly expressed in MIR126-transfected H28 cells,
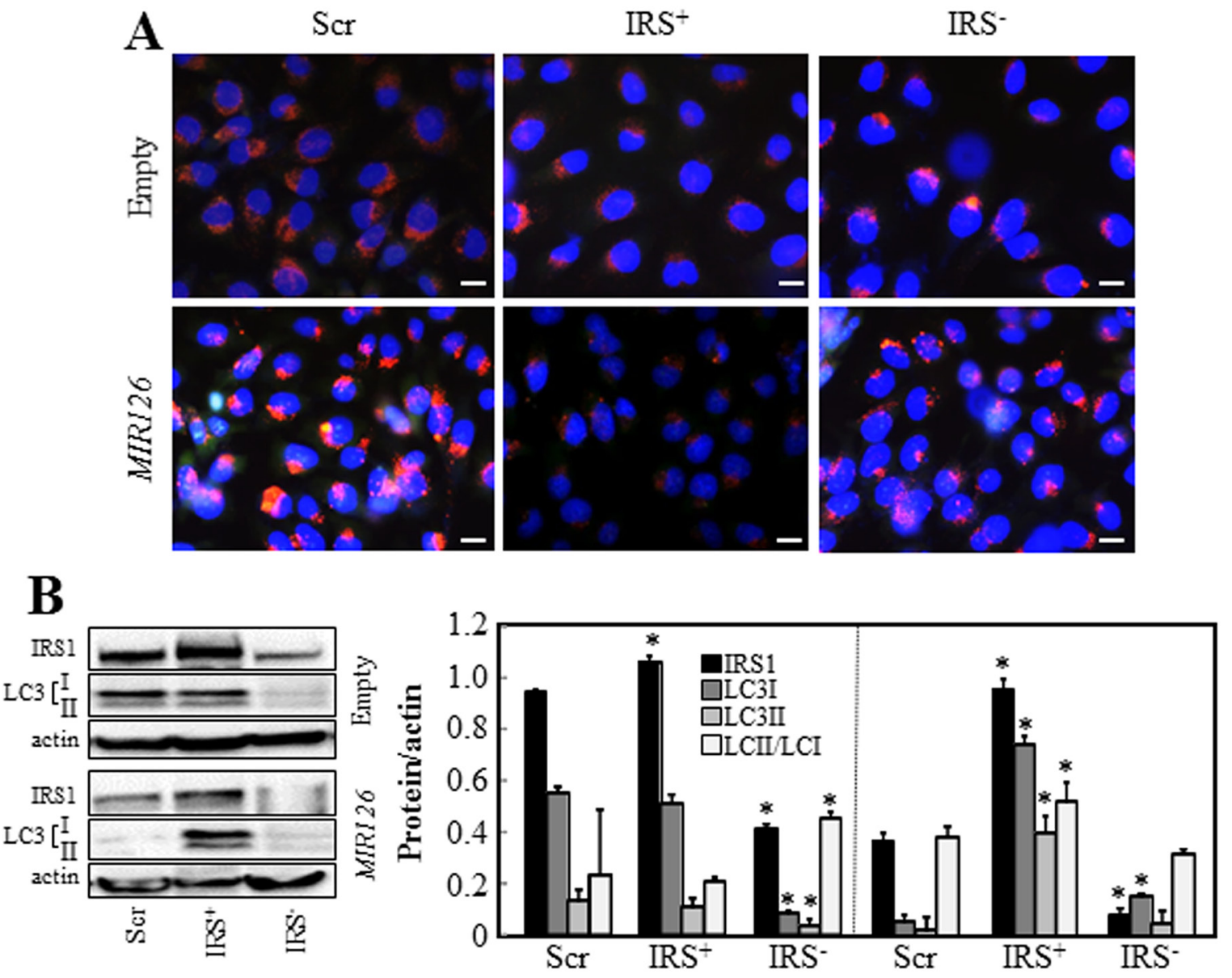

Figure 2: IRS1 is involved in MIR126-induced autophagy. Empty plasmid- and MIR126-transfected H28 cells, and their IRS1silenced (IRS1-) or IRS1-overexpressing (IRS1+) counterparts were analyzed for AV formation A. IRS1 levels and LC3 conversion B. Densitometric analysis of IRS1 and LC3 conversion related to actin (right panel). Scale bar for all images equals $10 \mu \mathrm{m}$. The data shown are mean values \pm S.D. derived from three independent experiments. Comparisons among groups were determined by one-way ANOVA with Tukey post-hoc analysis; the symbol "*" indicates significantly different values compared with scramble control with $p<0.05$. 
glucose uptake was markedly reduced in these cells also after insulin stimulus. Anti-MIR126 transfection restored glucose uptake in these cells (Supplementary Figure S1B). However, the high level of GLUT-4 found in MIRtransfected Met5A paralleled high glucose uptake. No significant changes in glucose uptake were observed in MIR126-non-responsive IstMes2 cells (Figure 3C).

\section{MIR126 regulates autophagy}

Limited availability of intracellular glucose can trigger autophagy. AMPK/mTOR signaling pathway, a major regulator of autophagy, plays a role in inhibition of autophagy via phosphorylation of UNC-51-like kinase 1 (ULK1), a component involved in initiation of the autophagic process. We evaluated the autophagic signaling pathway in MIR126- and empty plasmid-transfected cells. Ectopic MIR126 increased mTOR expression in $\mathrm{H} 28$ cells but not in Met5A and IstMes 2 cells. The p-mTOR/ mTOR ratio, which indicates activation of $\mathrm{mTOR}$, increased in H28 cells overexpressing MIR126 (Figure 4A). Similarly, phosphorylation of the p70 ribosomal protein S6 kinase-1 (p70S6K), a downstream substrate of mTOR, was also increased in MIR126-transfected H28 cells. Overexpression of MIR126 induced the AMPK phosphorylation, which in turn activated the ULK1 pathway. Increased phosphorylation of ULK1 at Ser-555 (pro-autophagic) and decreased phosphorylation at Ser757 (anti-autophagic) were found in MIR-transfected H28 cells, but not in non-malignant Met5A cells and MIR126non-responsive IstMes 2 cells (Figure 4B). Restoration of the autophagic pathway was observed by blocking the function of MIR126 using antisense MIR126 (anti-MIR) (Figure S1C), further confirming the involvement of MIR126.

\section{Ectopic MIR126 induces lipid accumulation in malignant cells}

We observed vesicle-like particles in the cytoplasm of MIR126-transfected H28 cells. Staining with Oil Red $\mathrm{O}$ revealed that the vesicles contain lipid droplets (LDs) (Figure 5A, left panels). The LD formation in MIR126-transfected H28 cells was inhibited by antiMIR transfection (Figure S1A lower panel). This finding was supported by TEM (Figure 5A, right panels). Interestingly, mitochondria showed altered morphology, such as swollen appearance, which was not observed in control cells. We next investigated markers of mitophagy in MIR126-transfected cells. As shown in Figure 5B, ectopic MIR126 induced PARK2 and SQSTM1accumulation in isolated mitochondria of $\mathrm{H} 28$
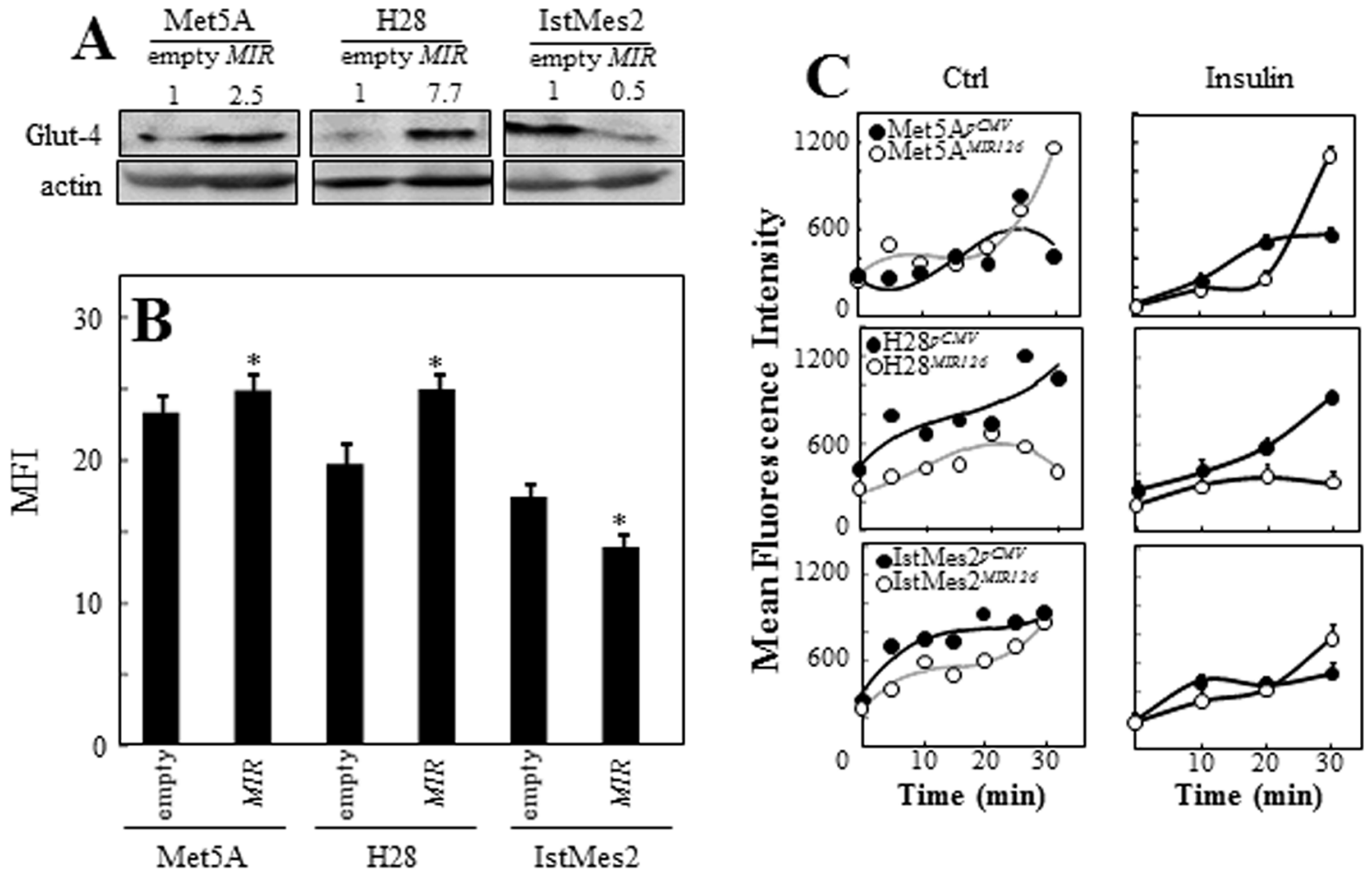

Figure 3: MIR126 induces GLUT-4 expression and inhibits glucose uptake. MIR126-transfected Met5A, H28 and IstMes2 cells and their empty plasmid-transfected counterparts were evaluated for GLUT-4 expression by WB A. and its cell surface expression by flow cytometry B, C. Glucose uptake was evaluated over time by 2-NBDG (50 $\mu \mathrm{M})$ in low-glucose DMEM without and with insulin stimulus, and expressed as mean fluorescent intensity (MFI). The data shown are mean values \pm S.D. derived from five independent experiments. The symbol "*" indicates significant differences compared with empty plasmid-transfected cells. 
cells, indicating mitophagy. Mitophagy was confirmed in empty- and MIR-transfected H28 cells by EOS-LC3 co-localization with MitoTracker-stained mitochondria. As shown in Figure 5C, the LC3 punctae co-localized with mitochondria, being indicative of mitophagic process. Formation of LDs and presence of damaged mitochondria/mitophagy were not observed in MIR126non-responsive IstMes2 cells (Figure 5).

Previous work demonstrated activation and stabilization of hypoxia-inducible factor- $1 \alpha$ (HIF $1 \alpha)$ in MIR126-transfected MM cells [12]. To assess whether MIR126-induced LDs and autophagy/mitophagy could be attributed to HIF1 $\alpha$, the hypoxia factor was silenced in MIR126-transfected H28 cells. A marked increase of LD accumulation was observed in parental cells with silenced HIF $1 \alpha$, while disappearance of LDs was found in their MIR126-transfected counterparts (Figure S4, left panels). HIF $1 \alpha$ did not affect AV formation and the autophagy signaling pathway (Figure S4A, right panels). Conversely, increased GLUT-4 and PARK2 induced by MIR126 was reversed by HIF $1 \alpha$-silencing, pointing to a HIF-dependent mechanism (Supplementary Figure S4B).
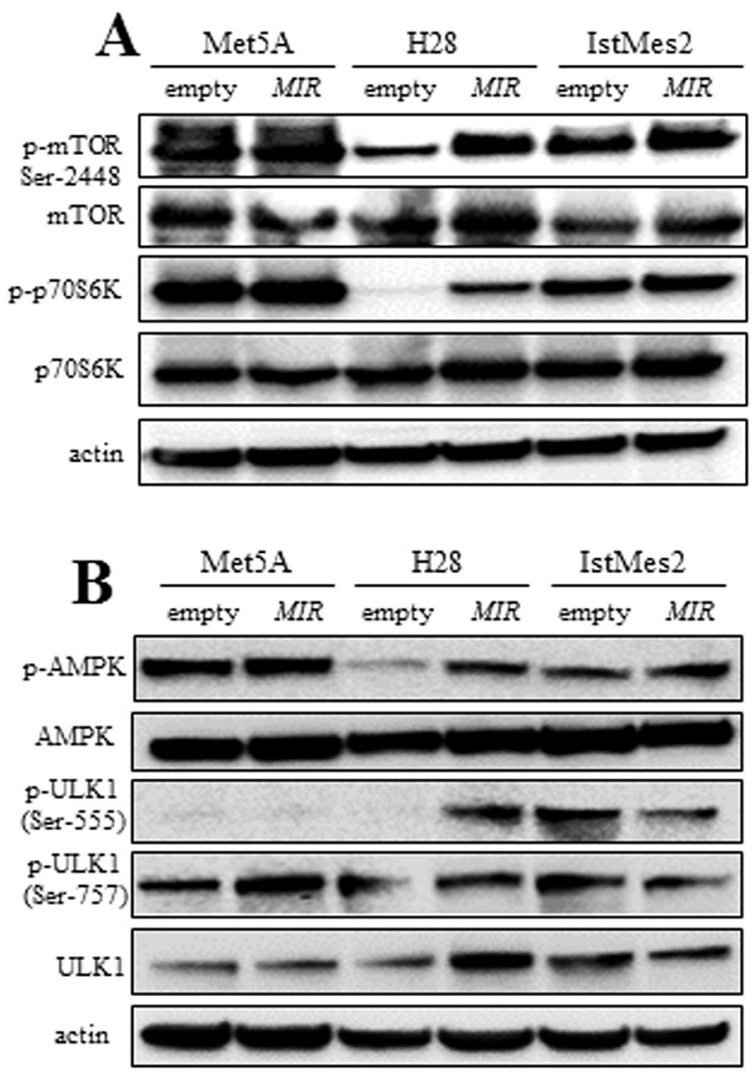

\section{MIR126 induces autophagy by inhibiting PDK and $A C L$}

A global picture of modulation of signaling pathways by MIR126 was investigated by genome-wide gene expression analysis. We utilized the pathway enrichment analysis to compare MIR126-transfected cells with their empty vector-transfected counterparts (Figure S5). Ectopic MIR126 regulated a number of genes, affecting different signaling pathways. These include various pathways involved in cancer, such as the MAPK pathway, DNA synthesis and repair, IGF regulation, angiogenesis, or the Wnt pathway, as well as pathways regulating senescence and autophagy (Supplementary Figure S5A).

Gene array analysis revealed that one of the most profoundly downregulated genes in MIR 126-transfected H28 cells was pyruvate dehydrogenase kinase (PDK) (Supplementary Figure S5B). The PDK protein inhibits mitochondrial pyruvate dehydrogenase (PDH), which catalyses irreversible decarboxylation of pyruvate to acetyl-CoA (AcCoA). Paradoxically, downregulation of PDK by MIR 126 resulted in reduction of $\mathrm{PDH}$ activity
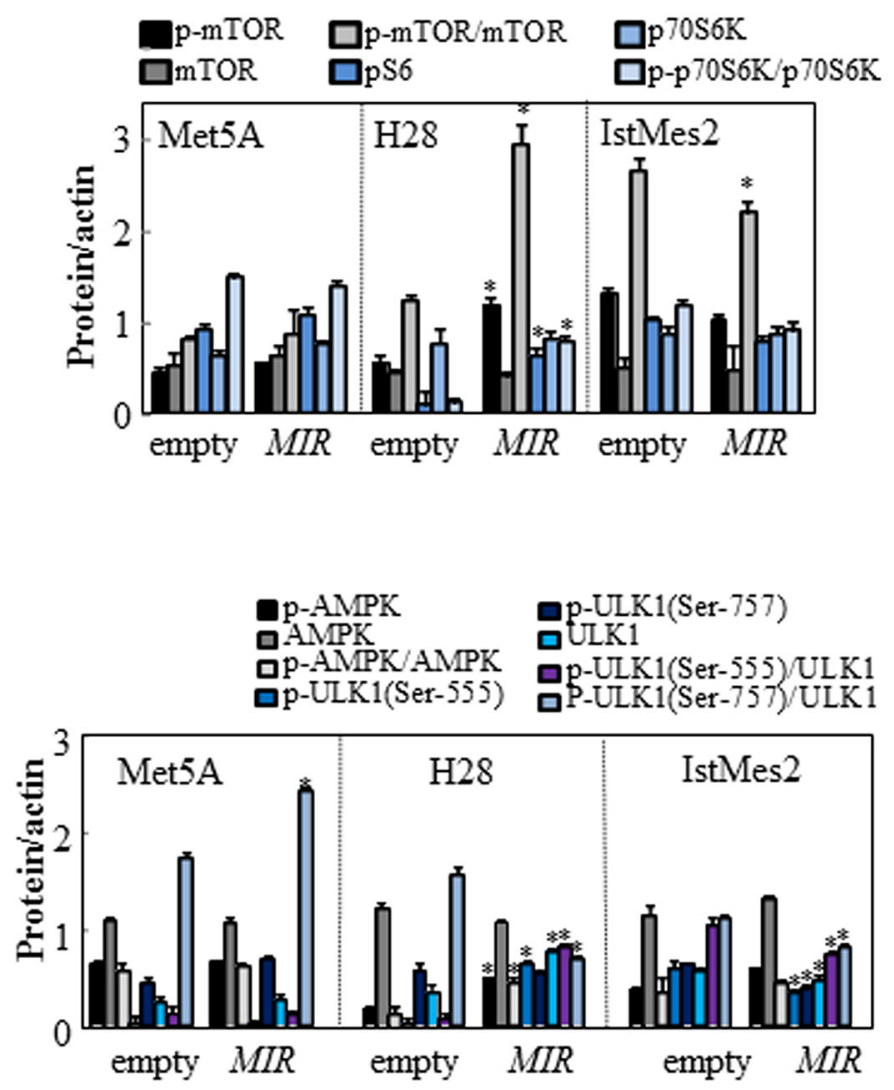

Figure 4: MIR126 affects the mTOR/AMPK/ULK1 pathway. MIR126-transfected Met5A, H28 and IstMes2 cells and their empty plasmid-transfected counterparts were analyzed for relative levels of p-mTOR, mTOR and p-p70S6K, p70S6K A. and for p-AMPK, AMPK, p-ULK1 (Ser555), p-ULK1 (Ser757) and ULK1 B. Densitometric evaluation of the bands shown relative to actin (right panels). The data shown are mean values \pm S.D. derived from five independent experiments. The symbol "*” indicates significant differences compared with empty plasmid-transfected cells. 


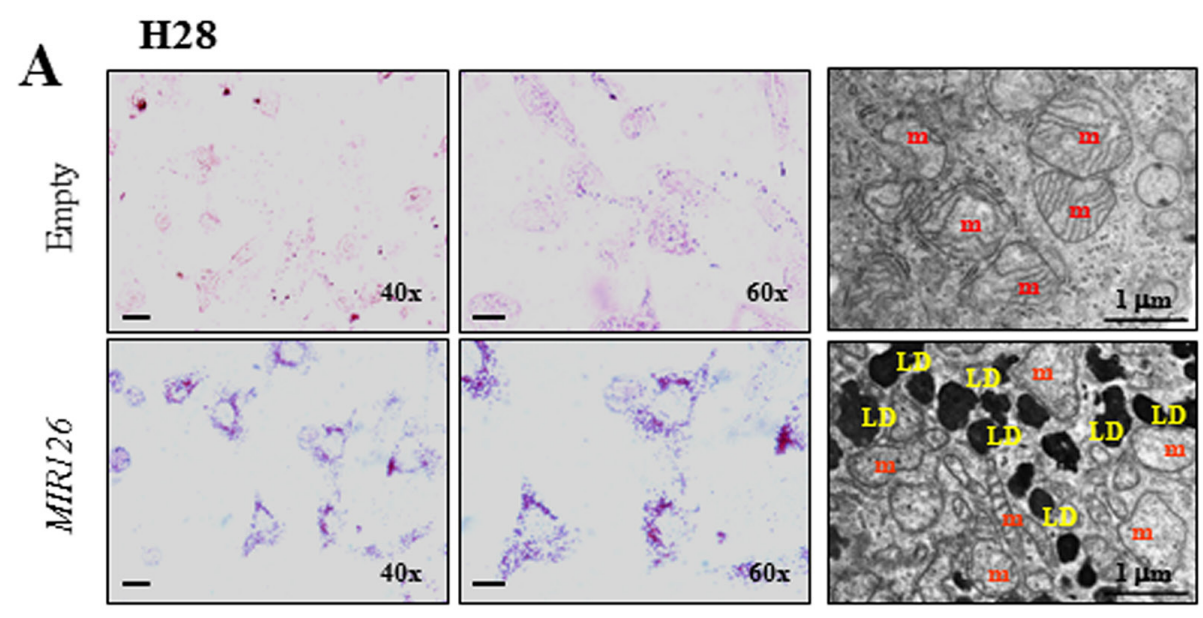

\section{IstMes2}
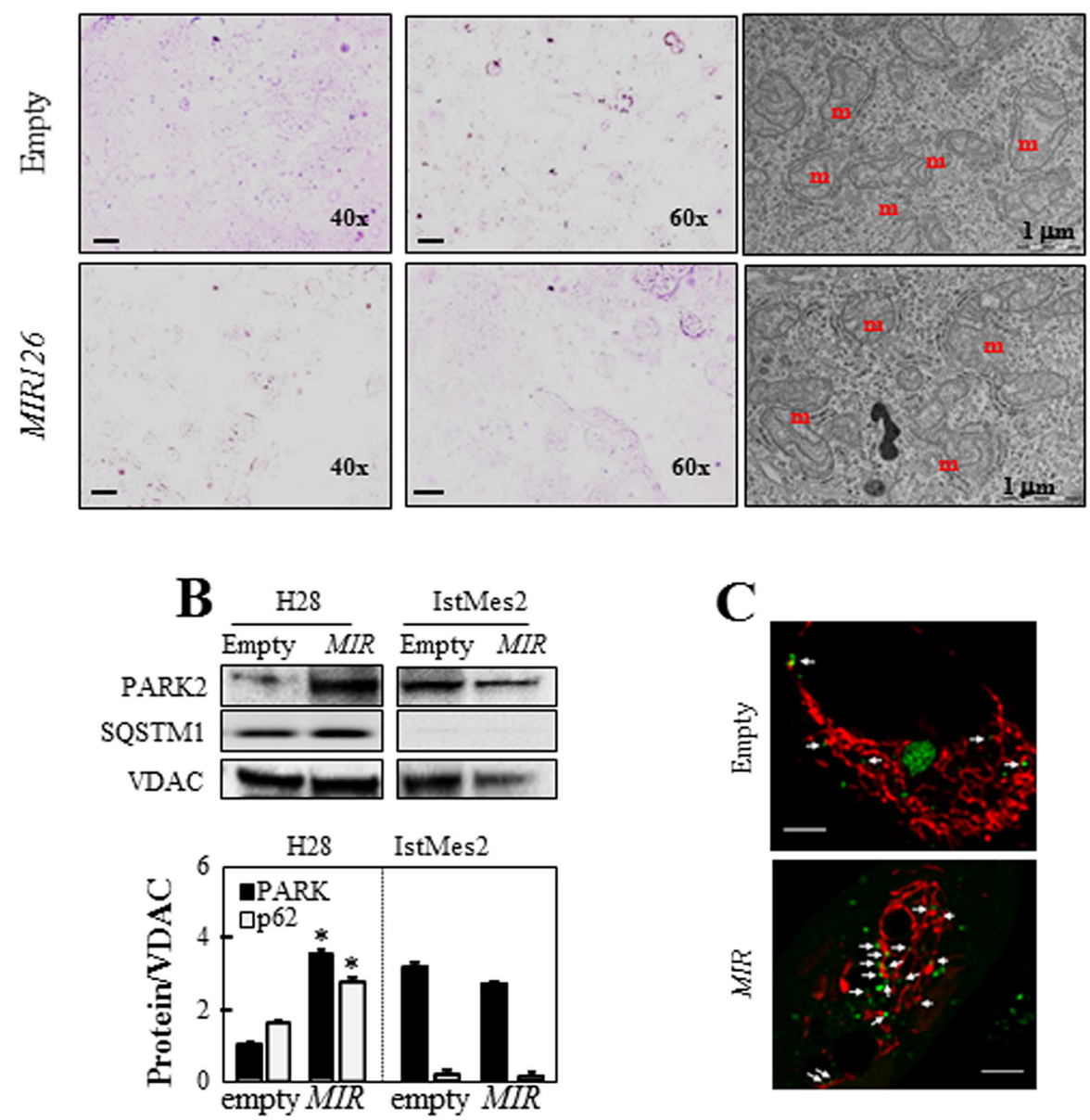

Figure 5: MIR126 overexpression results in lipid accumulation. A. H28 and IstMes2 cells transfected with empty plasmid and MIR126 were subjected to Oil Red O staining (left panel), and TEM (right panel). Magnification/scale bar are shown in individual images; $\mathrm{m}=$ mitochondria, LD = lipid droplet. B. Immunoblot of PARK2, SQSTM1, and cytochrome c (cyt c) in mitochondria isolated from MIR126-transfected H28 and IstMes2 cells and their empty plasmid-transfected counterparts. Densitometric analysis related to voltagedependent anion channel (VDAC) is shown in the bottom panel. C. EOS-LC3 co-localization with mitochondria stained with MitoTracker Far Red in empty- and MIR126-transfected H28 cells. The LC3 punctae decorating mitochondria are indicated by white arrows. Scale bar equals $5 \mu \mathrm{m}$. The data shown are mean values \pm S.D. derived from three independent experiments. The symbol "*" indicates significant differences compared with empty plasmid-transfected cells. 
associated with an increase of its substrate, pyruvate, in malignant H28 cells (Figure 6A, 6B). In our previous work, we reported that MIR126 increased cellular citrate by inhibiting the ACL activity [12]. Therefore, to evaluate the role of PDK and ACL in the mediation of MIR126 effect, H28 cells were silenced for ACL activity, and PDK was inhibited by treatment with dichloroacetate (DCA). As shown in Figure 6C, DCA applied as a single agent induced $\mathrm{PDH}$ activity, consistent with its PDKinhibitory role. Interestingly, ACL silencing markedly reduced $\mathrm{PDH}$ activity, which was also observed in DCAtreated $\mathrm{H} 28$ cells. In these cells, pyruvate levels increased (Figure 6D), thus resembling MIR126-transfected H28 cells with low PDH activity and high pyruvate level. These metabolic changes resulted in AV formation and LD accumulation, which were associated with inhibition of cell proliferation and colony-forming activity (Figure 7A-7D). Since these effects of MIR126 in H28 cells are consistent with its tumor suppressor properties, we tested its effect on tumor growth. Figure 8 documents that while $\mathrm{H} 28^{\mathrm{pRS}}$ mock cells progressively formed tumors,
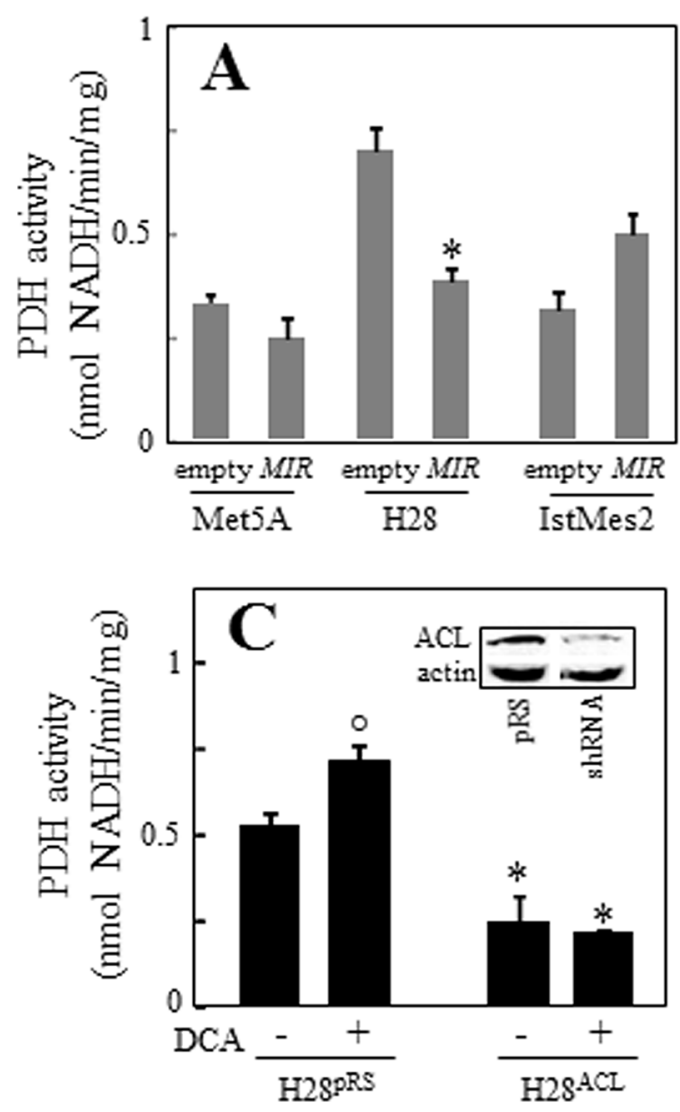

H28 MIRI26 MIR126-transfected cells formed small tumors that were resorbed by day 10 , reflecting the anti-tumor efficacy of MIR126 in vivo.

\section{DISCUSSION}

MIR126 has been reported to suppress progression of MM by affecting cellular metabolism [12]. Here, we found that MIR126 is a potent inducer of autophagy in MM cells. We discovered that ectopic MIR126-induced massive AV formation and increased autophagic flux via autophagosome/lysosome fusion, as indicated by increased LC3II turnover and increased delivery of LC3 into lysosomes ( $c f$ Figure 1). This MIR126-induced autophagic process is mediated by IRS1. Down-regulation of IRS1 by MIR126 or silencing of IRS1 reduced the LC3II/LC3I ratio as a result of high autophagic activity, which was reversed by IRS1 overexpression ( $c f$ Figure 2). IstMes2 MM cells lacking the MIR126-binding site within the IRS1 3'UTR further confirmed the role of IRS1 ( $c f$ Supplementary Figure S3).
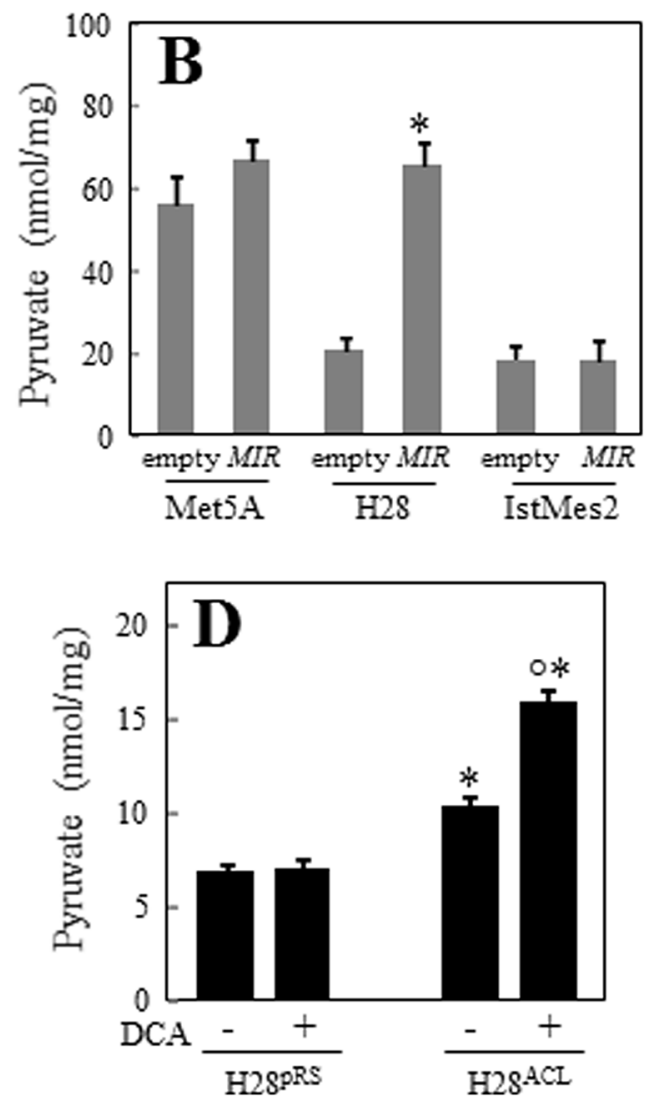

Figure 6: ACL and PDK knock-down increase pyruvate levels and affect PDH activity. MIR126 transfected Met5A, H28 and IstMes2 cells and their empty plasmid-transfected counterparts were analyzed for PDH activity A. and pyruvate levels B. H28 cells

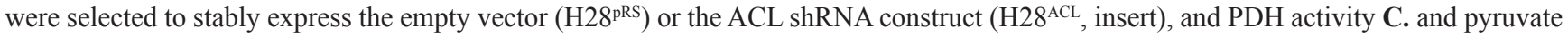
levels D. evaluated in the presence or absence of PDK inhibitor DCA $(20 \mathrm{mM})$. The data shown are mean values \pm S.D. derived from three independent experiments. Comparisons among groups were determined by one-way ANOVA with Tukey post-hoc analysis; the symbol "*" indicates significant differences compared with empty plasmid-transfected cells, and the symbol "o" indicates significance between DCA treated and untreated cells. 
Insulin receptor substrates (IRS), critical components of insulin signaling, are involved in cell proliferation, metabolism, and cancer development [24]. It was reported that IRS block basal autophagy via inhibition of PI3K/mTOR signaling [25]. Contrary to our expectation, MIR126 induced activation of the mTOR pathway in MM cells. MIR126-transfected H28 cells also showed activated AMPK/ULK1 pathway, a sensor of intracellular energy homeostasis [26] (cf Figure 4), suggesting that the AMPK/ULK1 pathway takes precedence in autophagy regulation upon MIR126 expression in MM cells. The increased AMPK activity could be related to reduced glucose uptake observed for MIR126 H28 cells, which was independent of GLUT4. Hence, the increased GLUT-4 in this scenario could result from compensatory upregulation driven by HIF $1 \alpha$ that we previously found to be increased by MIR 126 in MM cells [12]. In contrast, in non-malignant mesothelial cells, increased expression of GLUT-4 by MIR126 was associated with higher glucose uptake, pointing to very distinct effects of MIR126 in MM and non-malignant cells.

Surprisingly, MIR126 induced $\sim 50$-fold downregulation of PDK in MM cells, yet decreased $\mathrm{PDH}$ activity, even though an increase of PDH activity would be expected in this situation. PDK is a negative regulator of the mitochondrial PDH complex, which modulates the balance between oxidation of glucose and lipids, depending on the nutritional status, and plays role of metabolic switch for fuel selection [27]. Clinical evidence has shown that upregulation of PDK correlates with advanced malignancy [28, 29],
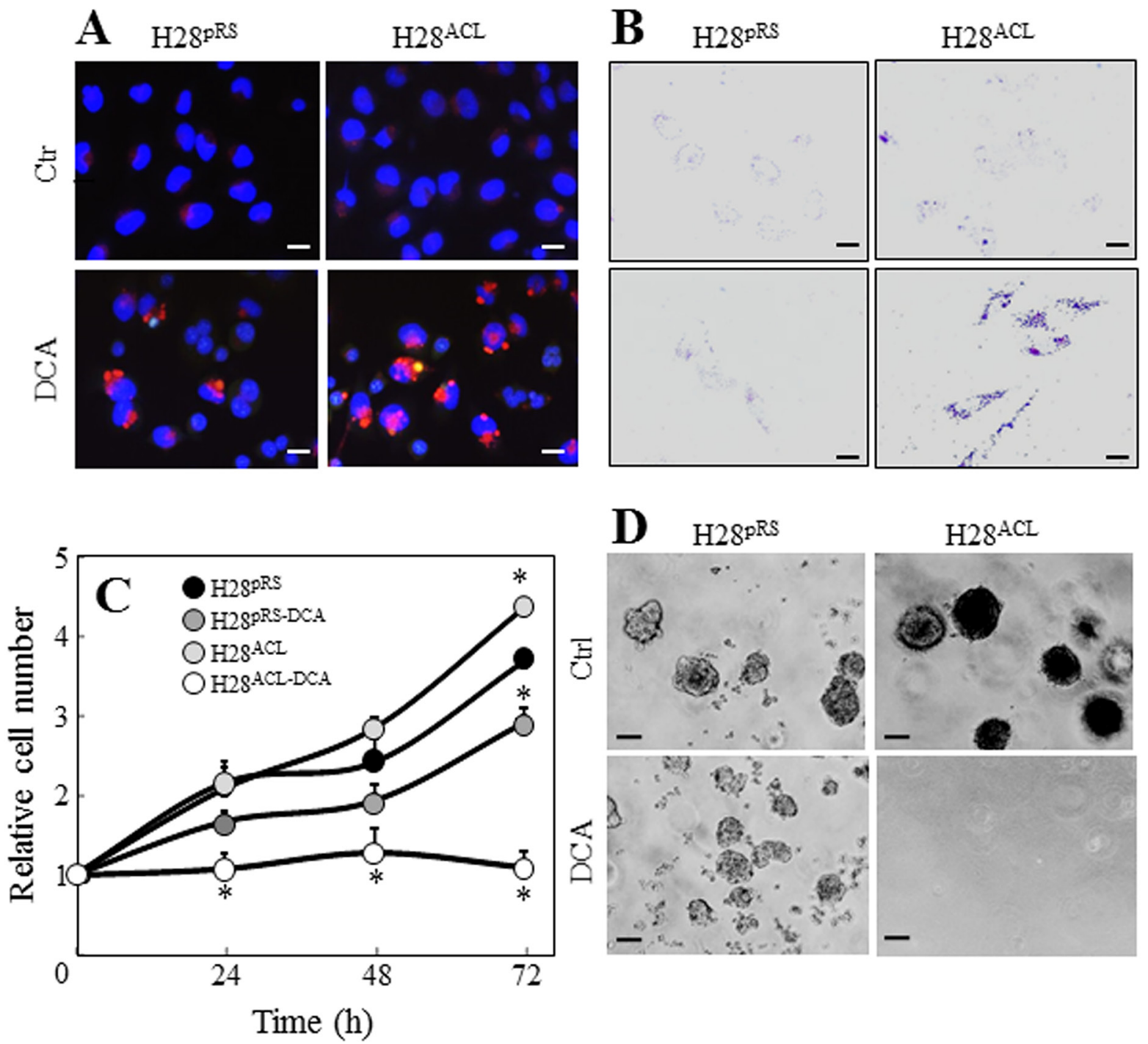

Figure 7: ACL and PDK knock-down promote autophagy and inhibit cell proliferation. Cells transfected with empty vector $\left(\mathrm{H} 28^{\mathrm{pRS}}\right)$ or ACL shRNA construct $\left(\mathrm{H} 28^{\mathrm{ACL}}\right)$ were evaluated for AV A. and LD B. formation, and for cell proliferation C. and colonyforming activity $\mathbf{D}$. in the presence and absence of DCA $(20 \mathrm{mM})$. Images are representative of three independent experiments. Scale bars for cell and soft agar images are $10 \mu \mathrm{m}$ and $100 \mu \mathrm{m}$, respectively. Comparisons among groups were determined by one-way ANOVA with Tukey post-hoc analysis; the symbol "*” indicates significant differences compared with empty vector-transfected cells. 
and its inhibition significantly suppresses tumor growth in mouse xenograft models [30,31]. Although ectopic MIR126 inhibited PDK, PDH activity was reduced in MIR126transfected H28 cells compared to their empty-plasmid counterparts.

Previously we have found that MIR 126 upregulation in MM cells decreased ACL activity, inducing citrate accumulation in the cytoplasm and stabilization of HIF $1 \alpha$ [12]. ACL is responsible for the conversion of citrate to cytosolic AcCoA, an important component of several biosynthetic pathways. In addition, cytosolic AcCoA can regulate autophagy by protein acetylation $[32,33]$. In this study, we found that simultaneous inhibition of PDK and ACL by pharmacological and genetic means recapitulated the effects of MIR126 on tumorigenic potential and autophagy, while single treatment had little or no effect. This means that PDK and ACL together are principal effectors of MIR126 response initiated at IRS1, which regulates ACL via AKT [12].

An interesting finding of this study is that ACL inhibition (by MIR126 or by genetic intervention) can override the removal of PDK-mediated control and maintain an inactive PDH complex. While the precise nature of this interesting phenomenon is not clear, it could be related to increased mitochondrial reducing activity and limited mitochondrial respiration previously reported in MIR126 MM cells [12], and reflect direct inhibition of $\mathrm{PDH}$ complex by increased level of mitochondrial NADH.
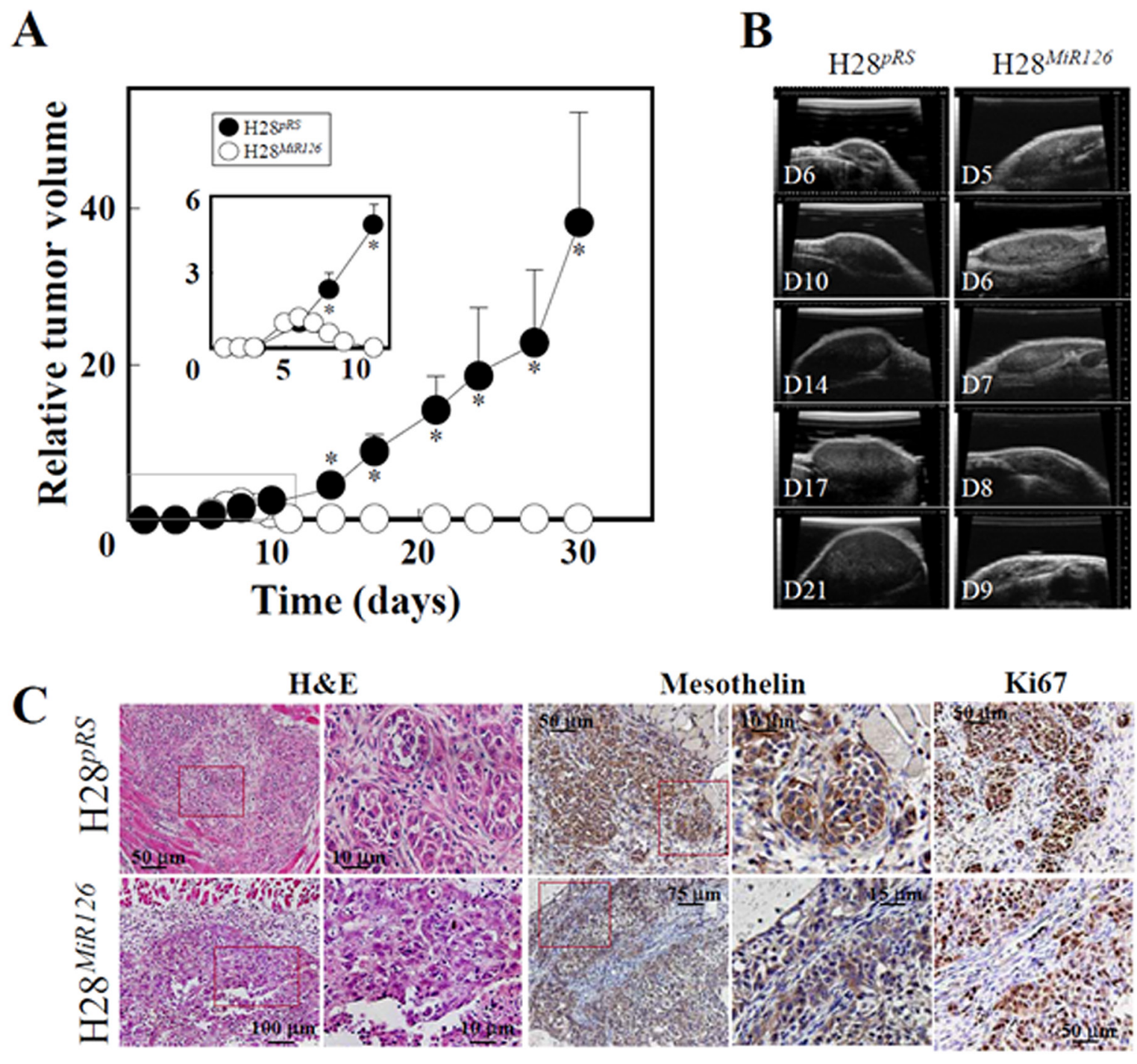

Figure 8: MIR126 suppresses tumor formation. A. Balb-c $n u / n u$ mice were injected subcutaneously with $1 \times 10^{6} \mathrm{H} 28^{\mathrm{pRS}}$ or $\mathrm{H} 28^{\mathrm{MiR} 126}$ cells and tumor growth was quantified by USI. The inset shows details of tumor size in the initial stage of the experiment. The results are derived from 6 mice in each group, and the symbol ' $*$ ' indicates significant differences with $p<0.05$. B. Shown here are representative images of tumors derived from the two $\mathrm{H} 28$ sublines acquired on individual days. C. Tumors from day 6 were sectioned and stained with $\mathrm{H} \& \mathrm{E}$, as well as subjected to immunohistochemistry using anti-mesothelin IgG to identify MM cells in the sections and anti-Ki67 IgG to see the level of proliferation of tumor cells. H\&E staining clearly documents lack of 'structure' of the H28 ${ }^{\text {MiR } 126}$ cell-derived tumors, which is obvious in tumors derived from cells transfected with the empty plasmid. 


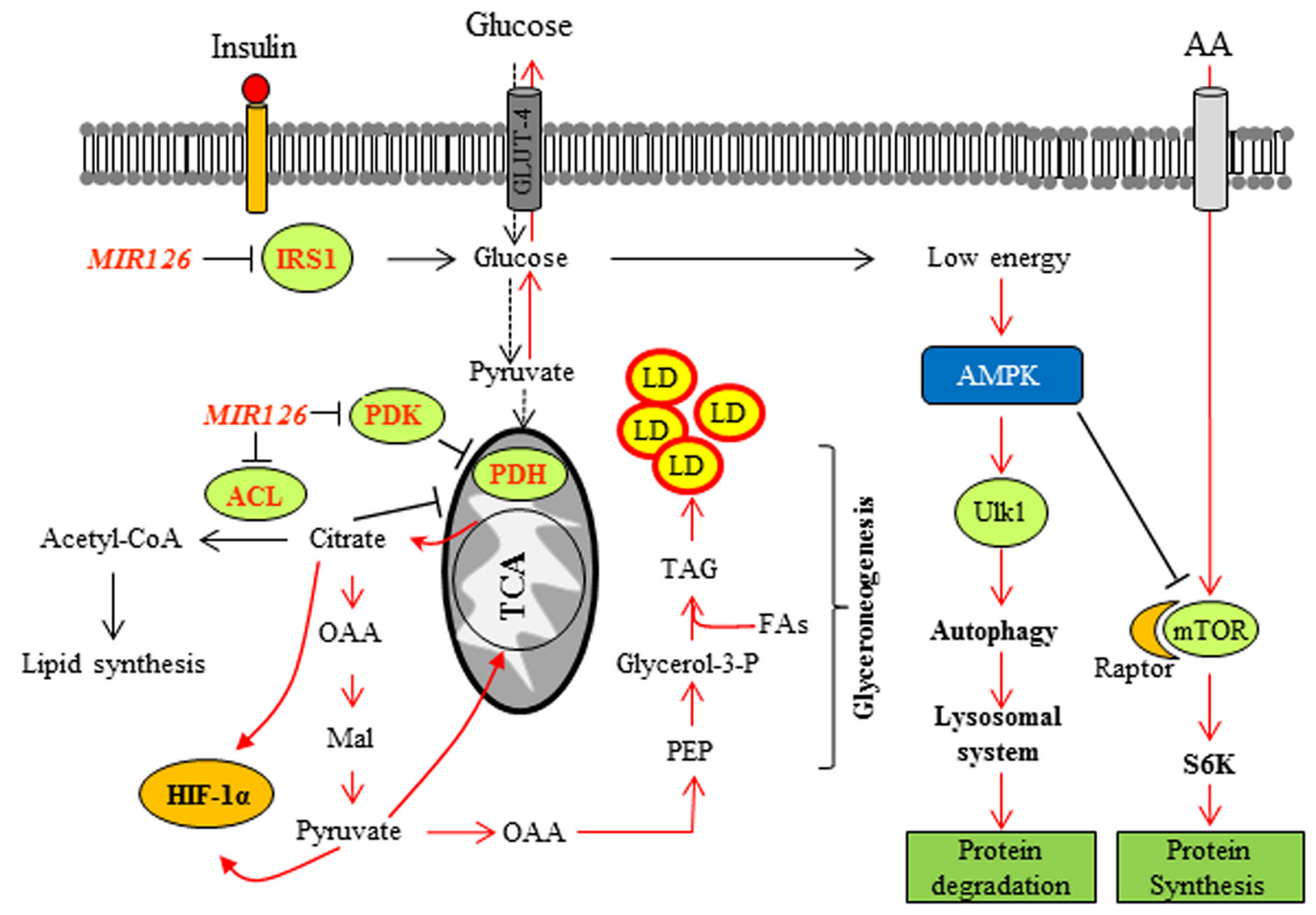

Figure 9: Proposed model of MIR126 in regulating autophagy and cell proliferation. MIR 126 targets the expression of IRS1 resulting in the insulin signaling pathway disruption. This contributes to lower glucose uptake. Upon energy depletion, the AMPK pathway is activated and induces lysosomal autophagy. Inhibition of ACL by MIR126 contributes to citrate accumulation in cytosol, inducing HIF $1 \alpha$ activation and stabilization, leading to GLUT-4 upregulation. MIR126 induces PDK down-regulation, which in conjunction with ACL inhibition paradoxically inhibits PDH, possibly due to the high level of NADH and citrate/pyruvate in mitochondrial matrix. The associated HIF1 $\alpha$ stabilization results in lipid droplets accumulation (LD) via increased 'glyceroneogenesis' [12]. This complex metabolic program leads to the loss of malignancy in MM. The activated pathways are shown in red. OAA, oxaloacetic acid; Mal, malic acid; PEP, phosphoenolpyruvate.

In addition, mitochondria compromised by MIR 126 in conjunction with higher autophagic flux instigate increased mitophagy observed in this study for MIR126expressing MM cells.

The accumulation of cytoplasmic lipids in LDs found in MIR126-transfected MM cells could result from direct replenishment of LD linked to increased autophagy [34], or it could relate to the elevated HIF1 $\alpha$ we previously identified in MIR126-expressing MM cells [12]. We consider the second option more likely, as we show that HIF $1 \alpha$ knock down did not affect autophagy in MIR126 MM cells, but eliminated LD formation. Therefore, not autophagy, but direct HIF1 $\alpha$ regulation, for example via hypoxia-inducible protein 2 (HIG2) which is a downstream target of HIF $1 \alpha$ implicated in LD biogenesis [35], is responsible for LD formation upon MIR126 expression.

In summary, we show that MIR126 induces complex metabolic reprogramming of $\mathrm{MM}$ cells including activation of the autophagic pathway following disruption of IRS signaling, downregulation of PDK and ACL activity, accumulation of citrate, and formation of LDs in the cytoplasm in a HIF1 $\alpha$-dependent manner (Figure 9). Collectively, these effects inhibit tumor progression when MIR126 is high, emphasizing the protective role of enhanced autophagic flux in the progression of MM.

\section{MATERIALS AND METHODS}

\section{Cell culture and treatments}

Non-malignant mesothelial cells (Met5A) and sarcomatoid MM cells (H28) were obtained from the ATCC. Immortalized IstMes2 cells (epithelioid) were established from a patient and were identified morphologically by a phenotypic analysis [36]. All cell lines were grown in the RPMI-1640 medium with antibiotics and $10 \%$ FBS. Cells were treated for $24 \mathrm{~h}$ with 3-methyladenine (3MA, $50 \mu \mathrm{M}$ ) or chloroquine (CQ, 10 $\mu \mathrm{M})$ to block autophagosome formation or autophagic degradation, respectively, and with dichloroacetate (DCA, $20 \mathrm{mM}$ ) to inhibit PDK activity. 


\section{MIR126, siRNA and transfections}

Cells $\left(2 \times 10^{5}\right)$ were stably transfected with $1 \mu \mathrm{g}$ of the pCMV-MiR and/or pRS (OriGene) empty plasmid or with plasmid carrying the MIR126 sequence 5'-UCG UAC CGU GAG UAA UAA UGC G-3' (OriGene, Rockville, MD) and/or shRNA pRS plasmid, with the HIF1 $\alpha$-targeting sequence of 5'-ACA AGA ACC TAC TGC TAA TGC CAC CAC TA-3', and with the acetylCoA citrate lyase (ACL)-targeting sequence of 5'-CCA TCA CTG AGG TCT TCA AGG AAG AGA TG-3', using the TransIT-LT1 reagent (Mirus). Selection was carried out with G418 (Sigma) and/or puromycin (Sigma) added to the cell culture media after transfection at 0.6 $\mathrm{mg} / \mathrm{ml}$ and $1 \mu \mathrm{g} / \mathrm{ml}$ for $48 \mathrm{~h}$, respectively. G418- and/or puromycin-resistant clones were analyzed for MIR126 and HIF $1 \alpha$ expression. Selected clones were maintained in RPMI with $0.6 \mathrm{mg} / \mathrm{ml} \mathrm{G} 418$ and $/$ or $1 \mu \mathrm{g} / \mathrm{ml}$ puromycin. Anti-IRS1 sequence 5'-AGA CCA UCA GCU UCG UGA ATT-3' (Ambion), or human IRS1 plasmid (SC124032, OriGene), were used to transiently silence or overexpress IRS1, respectively. MIR 126 function was blocked with the anti-sense oligonucleotide 5'-GCA UUA UUA CUC ACG GUA CGA-3' (IDT, Tema Ricerca). Scrambled sequences were used as a control. Cells $\left(2 \times 10^{5}\right)$ were transfected with the oligonucleotide $(1 \mu \mathrm{g} / \mathrm{well})$ using TransIT-LT1. After $48 \mathrm{~h}$, the levels of IRS1 mRNA were evaluated by WB analysis.

\section{Transfection with EOS-LC3 and EGFP- mCHERRY-LC3B vectors, image acquisition and analysis}

MIR126-transfected cells (Met5A, H28) and their empty-plasmid counterparts were transiently transfected with the pLENTI6.3 EOS-LC3 expression plasmid (a kind gift from Dr. P. Jezek, Institute of Physiology, CAS) or the dual fluorescence pBabe-puro-mCHERRYEGFP-LC3B vector [50] using Lipofectamine 3000 (Life Technologies) two days before the experiment in glass bottom microscopy dishes (In Vitro Scientific). For EOS-LC3 imaging, the mitochondria were stained with MitoTracker Far Red (20 nM, 15 min; Life Technologies), and for mCHERRY-EGFP-LC3 imaging, the cell nuclei were stained with Hoechst33342 (200 ng/ml, 15 min; Sigma). Images of live cultures were captured by Leica SP5 confocal microscope using HCX PL APO 63x/1,30 glycerol immersion objective, zoom 5, scanning speed $1,000 \mathrm{~Hz}$ and line averaging 2 at $37{ }^{\circ} \mathrm{C}$ and $5 \% \mathrm{CO}_{2}$. Images were deconvoluted with the Huygens professional software package (SVI). The scoring for yellow/green (autophagosomes) and red dots (autophagosomes inside lysosomes) produced by the dual fluorescence mCHERRYEGFP- LC3B vector was done manually in ImageJ. The dots were scored as red only when no signal was detected in the green channel.

\section{Acid vesicles (AVs) and mitochondrial staining}

For detection of AVs, cells were seeded on coverslips, allowed to attach overnight, and incubated with $5 \mu \mathrm{g} / \mathrm{ml} \mathrm{AO} \mathrm{(Sigma)} \mathrm{for} 30 \mathrm{~min}$ at $37^{\circ} \mathrm{C}$. Mitochondria were visualized with $200 \mathrm{nM}$ tetramethyl rhodamine methyl ester (TMRM, Invitrogen). Cells were analyzed using confocal microscopy (Zeiss, Axiocam MRc5; magnification $40 \mathrm{x}$ or $60 \mathrm{x}$ ).

\section{Western blot analysis}

Cells or isolated mitochondria were lysed in the RIPA buffer containing $\mathrm{Na}_{3} \mathrm{VO}_{4}(1 \mathrm{mM})$ and protease inhibitors $(1 \mu \mathrm{g} / \mathrm{ml})$. The cell lysate proteins were separated using SDS-PAGE and transferred onto nitrocellulose membranes (Protran). After blocking with $5 \%$ non-fat milk in PBS-Tween $(0.1 \%)$, the membranes were incubated with antibodies against IRS1, HIF1 $\alpha$ (both Bethyl), BECN1, SQSTM1/p62, LC3B, phosphorp70S6K, phospho-AMPK, AMPK, phospho-ULK1 (Ser-555), phospho-ULK1 (Ser-757), and ULK1 (all Cell Signaling), phospho-mTOR (p-mTOR, Ser-2448), mTOR, PARK2 (all ThermoFisher Scientific), and GLUT-4, cytochrome c and VDAC1 (all Santa Cruz). After incubation with the HRP-conjugated secondary IgG (Sigma), blots were developed using the ECL detection system (Pierce Biotechnology). The band intensities were visualized and quantified with ChemiDoc using the Quantity One software (BioRad Laboratories).

\section{Glucose uptake}

Cells were seeded in 96-well black-bottom plates $\left(2 \times 10^{4}\right.$ cells per well) and incubated in DMEM with low glucose $(1 \mathrm{~g} / \mathrm{l})$ overnight at $5 \% \mathrm{CO}_{2}$ and $37^{\circ} \mathrm{C}$. The cells were then incubated for 30 min with $50 \mu \mathrm{M}$ 2-nitrobenzodeoxyglucose (2-NBDG) in low-glucose DMEM without or with insulin $(50 \mu \mathrm{g} / \mathrm{ml})$. The level of fluorescent glucose analogue in the cells was evaluated at 550/590 $\mathrm{nm}$ using a fluorescence plate reader (Infinite F200 PRO, Tecan).

\section{Oil Red O staining of lipids}

Cells grown on coverslips were fixed in $70 \%(\mathrm{v} / \mathrm{v})$ cold ethanol before staining with Oil Red O solution in $60 \%(\mathrm{v} / \mathrm{v})$ isopropanol. For visualization, bright-field images were captured at 40x and 63x magnification using the Axiocam MRc5 fluorescence microscope (Zeiss).

\section{Transmission electron microscopy (TEM)}

Cells were fixed in $2.5 \%$ glutaraldehyde in phosphate-buffered saline (PBS) for $4 \mathrm{~h}$ and centrifuged to form pellets. The pellets were then rinsed in $0.1 \mathrm{M}$ cacodylate buffer (Electron Microscopy Sciences), post- 
fixed in $1 \%$ osmium tetroxide for $30 \mathrm{~min}$ at $4^{\circ} \mathrm{C}$, processed with propylene oxide, and embedded in mixture of EponAraldite. Thin sections were obtained with an LKB NOVA ultratome (Bromma), stained with lead citrate, and examined using the Philips CM 10 TEM.

\section{Soft agar colony formation}

Cells were seeded in $0.7 \%$ low melting point agar in 24-well plates, overlaid with $0.35 \%$ low melting point agar, and cultured at $37^{\circ} \mathrm{C}$ in $5 \% \mathrm{CO}_{2}$ for 1 month. Every 7 days, $0.5 \mathrm{ml}$ of fresh medium was added to each well and the number of colonies counted.

\section{Isolation of mitochondria}

Mitochondria were isolated from H28 and IstMes2 MIR126-transfected cells and their empty plasmidtransfected counterparts using a commercial kit (Sigma) according to the manufacturer's instructions. The results were normalized to the total protein determined using the Bradford assay (Sigma).

\section{Evaluation of pyruvate and pyruvate dehydrogenase (PDH) activity}

Intracellular pyruvate and $\mathrm{PDH}$ activity were evaluated using a colorimetric kit (Sigma) according to the manufacturer's protocol. The results were normalized to the total protein.

\section{Gene expression microarray}

Gene expression was assessed using the Agilent 44K microarray technology. Total RNA from MIR126- and empty plasmid-transfected $\mathrm{H} 28$ cells was isolated using the RNeasy kit (Qiagen) following the manufacturer's protocols. Total RNA (1 $\mu \mathrm{g})$ was converted to labelled cRNA with nucleotides coupled to a fluorescent dye (Cy3) using the QuickAmp Kit (Agilent Technologies). Universal RNA from Invitrogen was labeled with Cy5 as a reference. Samples were purified using the RNeasy kit and quantified for dye integration using Nanodrop-8000 (Thermo Scientific). Following quantification, samples were hybridized overnight in a rotating hybridization oven and washed/scanned using an Agilent scanner. Microarrays were processed by normexp background correction and loess normalization. Pathways enrichment analysis was performed using Gene Spring software version 12.

\section{Animal experiments}

Balb-c $n u / n u$ mice were injected subcutaneously with $1 \times 10^{6} \mathrm{H} 28^{\mathrm{pRS}}$ or $\mathrm{H} 28^{\mathrm{MiR} 126}$ cells per animal resuspended in $100 \mu \mathrm{l}$. Tumor volume was monitored by the ultrasound imaging (USI) instrument Vevo770 (VisualSonics) as described previously [37]. Each experimental group contained 6 mice. On day 6-7, representative tumors were excised from euthanized mice, paraffin-embedded, sectioned and stained with hematoxylin/eosin (H\&E) as well as subjected to immunohistochemistry using anti-mesothelin IgG and anti-Ki67 IgG, following a standard procedure. All experiments were approved by the Griffith University Ethics Committee and performed according to the guidelines of the Australian and New Zealand Council for the Care and Use of Animals in Research and Teaching.

\section{Statistics}

Results are expressed as mean \pm S.D. unless indicated otherwise. Comparisons among groups of data were made using one-way ANOVA with Tukey post hoc analysis. The two-tailed Student's t-test was used to compare two groups. Differences with $\mathrm{p}<0.05$ were considered statistically significant. All data generated in this study were analyzed using the SPSS software.

\section{ACKNOWLEDGMENTS}

We would like to Dr. P. Jezek, Institute of Physiology CAS, Prague for the kind gift of the pLenti6.3EOS-LC3B vector.

\section{CONFLICTS OF INTEREST}

The authors declare no conflict of interest

\section{GRANT SUPPORT}

This work was supported by a grant from National Institute against Occupational Injury Insurance (INAIL, P998), Italy, by the Australian Research Council, Cancer Council Queensland and Czech Science Foundation grant no. P301/10/1937 to J.N., Czech Science Foundation grant no. 16-22823S to J. R. as well as by BIOCEV European Regional Development Fund CZ.1.05/1.1.00/02.0109. We would like to thank for the financial support TACR (TE01020118), IMG (RVO:68378050), MEYS CR (LM2015062 CzechBioImaging).

\section{REFERENCES}

1. Cairns RA, Harris IS, Mak TW. Regulation of cancer cell metabolism. Nat Rev Cancer. 2011; 11:85-95.

2. Liu H, He Z, Simon H. Protective role of autophagy and autophagy-related protein 5 in early tumorigenesis. J Mol Med. 2015; 93:159-164.

3. Gozuacik D, Kimchi A. Autophagy as a cell death and tumor suppressor mechanism. Oncogene. 2004; 23:2891-2906. 
4. Green DR, Galluzzi L, Kroemer G. Metabolic control of cell death. Science 2014; 345:125-156.

5. Kenific CM, Debnath J. Cellular and metabolic functions for autophagy in cancer cells. Trends Cell Biol. 2015; 25:37-45.

6. Kim KM, Kim SG. Autophagy and microRNA dysregulation in liver diseases. Arch Pharm Res. 2014; 37:1097-1116.

7. Ebrahimi F, Gopalan V, Smith RA, Lam AK. MiR-126 in human cancers: clinical roles and current perspectives. Exp Mol Pathol. 2014; 96:98-107.

8. Tai HC, Chang AC, Yu HJ, Huang CY, Tsai YC, Lai YW, Sun HL, Tang CH, Wang SW. Osteoblast-derived WNT-induced secreted protein 1 increases VCAM-1 expression and enhances prostate cancer metastasis by down-regulating miR-126. Oncotarget 2014;5:7589-7598. doi: 10.18632/oncotarget.2280.

9. Chakraborty C, Sharma AR, Patra BC, Bhattacharya M, Sharma G, Lee SS. MicroRNAs mediated regulation of MAPK signaling pathways in chronic myeloid leukemia. Oncotarget 2016 Mar 8., in press, doi: 10.18632/ oncotarget. 7977.

10. Guo C, Sah JF, Beard L, Willson JK, Markowitz SD, Guda $\mathrm{K}$. The noncoding RNA, miR-126, suppresses the growth of neoplastic cells by targeting phosphatidylinositol 3-kinase signaling and is frequently lost in colon cancers. Genes Chromosomes Cancer, 2008; 47:939-946.

11. Chen SW, Wang TB, Tian YH, Zheng YG. Downregulation of microRNA-126 and microRNA-133b acts as novel predictor biomarkers in progression and metastasis of non small cell lung cancer. Int. J. Clin. Exp. Pathol. 2015;8:14983-14988.

12. Tomasetti M, Nocchi L, Staffolani S, Manzella N, Amati M, Goodwin J, Kluckova K, Nguyen M, Strafella E, Bajzikova M, Peterka M, Lettlova S, Truksa J, et al. MicroRNA-126 suppresses mesothelioma malignancy by targeting IRS1 and interfering with the mitochondrial function. Antioxid Redox Signal. 2014; 21:2109-2125.

13. Zhang J, Du YY, Lin YF, Chen YT, Yang L, Wang HJ, Ma D. The cell growth suppressor, mir-126, targets IRS-1. Biochem Biophys Res Commun. 2008; 377:136-140.

14. Ryu HS, Park SY, Ma D, Zhang J, Lee W. The induction of microRNA targeting IRS-1 is involved in the development of insulin resistance under conditions of mitochondrial dysfunction in hepatocytes. PLoS One. 2011; 6:e17343.

15. Felli N, Felicetti F, Lustri AM, Errico MC, Bottero L, Cannistraci A, De Feo A, Petrini M, Pedini F, Biffoni M, Alvino E, Negrini M, Ferracin M, et al. MiR-126 \& 126* restored expressions play a tumor suppressor role by directly regulating ADAM9 and MMP7 in melanoma. PLoS One. 2013; 8:e56824.

16. Hara T, Jones MF, Subramanian M, Li XL, Ou O, Zhu Y, Yang Y, Wakefield LM, Hussain SP, Gaedcke J, Ried T, Luo J, Caplen NJ, et al. Selective targeting of KRAS-mutant cells by miR-126 through repression of multiple genes essential for the survival of KRAS-mutant cells. Oncotarget. 2014; 5:7635-7650. doi: 10.18632/oncotarget.2284.

17. Yang C, Hou C, Zhang H, Wang D, Ma Y, Zhang Y, Xu $\mathrm{X}$, Bi Z, Geng S. MiR-126 functions as a tumor suppressor in osteosarcoma by targeting Sox2. Int J Mol Sci. 2013; $15: 423-437$

18. Miko E, Margitai Z, Czimmerer Z, Várkonyi I, Dezso B, Lányi A, Bacsó Z, Scholtz B. MiR-126 inhibits proliferation of small cell lung cancer cells by targeting SLC7A5. FEBS Lett. 2011; 585:1191-1196.

19. Sun Y, Bai Y, Zhang F, Wang Y, Guo Y, Guo L. MiR-126 inhibits non-small cell lung cancer cells proliferation by targeting EGFL7. Biochem Biophys Res Commun. 2010; 391:1483-1489.

20. Chen H, Li L, Wang S, Lei Y, Ge Q, Lv N, Zhou X, Chen C. Reduced miR-126 expression facilitates angiogenesis of gastric cancer through its regulation on VEGF-A. Oncotarget. 2014; 5:11873-11885. doi: 10.18632/oncotarget.2662.

21. Wu YT, Tan HL, Shui G, Bauvy C, Huang Q, Wenk MR, Ong CN, Codogno P, Shen HM. Dual role of 3-methyladenine in modulation of autophagy via different temporal patterns of inhibition on class I and III phosphoinositide 3-kinase. J Biol Chem. 2010; 285:10850-10861.

22. Meijer AJ, Codogno P. Autophagy: regulation and role in disease. Crit Rev Clin Lab Sci. 2009; 46:210-240.

23. Marín-Juez R, Diaz M, Morata J, Planas JV. Mechanisms regulating GLUT4 transcription in skeletal muscle cells are highly conserved across vertebrates. PLoS One. 2013; 8:e80628.

24. Geng Y, Ju Y, Ren F, Qiu Y, Tomita Y, Tomoeda M, Kishida M, Wang Y, Jin L, Su F, Wei C, Jia B, Li Y, Chang Z. Insulin receptor substrate $1 / 2$ (IRS1/2) regulates Wnt/ $\beta$ catenin signaling through blocking autophagic degradation of disheveled-2. J Biol Chem. 2014; 289:11230-11241.

25. Chan SH, Kikkawa U, Matsuzaki H, Chen JH, Chang WC. Insulin receptor substrate-1 prevents autophagy-dependent cell death caused by oxidative stress in mouse NIH/3T3 cells. J Biomed Sci. 2012; 19:64.

26. Mihaylova MM, Shaw RJ. The AMPK signalling pathway coordinates cell growth, autophagy and metabolism. Nat Cell Biol. 2011;13:1016-1023.

27. Sugden MC, Bulmer K, Holness MJ. Fuel-sensing mechanisms integrating lipid and carbohydrate utilization. Biochem Soc Trans. 2001; 29:272-278.

28. Koukourakis MI, Giatromanolaki A, Sivridis E, Gatter KC, Harris AL. Pyruvate dehydrogenase and pyruvate dehydrogenase kinase expression in non-small cell lung cancer and tumor-associated stroma. Neoplasia. 2005; 7:1-6.

29. Lu CW, Lin SC, Chien CW, Lee CT, Lin BW, Lee JC, Tsai SJ. Overexpression of pyruvate dehydrogenase kinase 3 increases drug resistance and early recurrence in colon cancer. Am J Pathol. 2011; 179:1405-1414. 
30. McFate T, Mohyeldin A, Lu H, Thakar J, Henriques J, Halim N D, Wu H, Schell MJ, Tsang TM, Teahan O, Zhou $\mathrm{S}$, Califano JA, Jeoung NH, et al. Pyruvate dehydrogenase complex activity controls metabolic and malignant phenotype in cancer cells. J Biol Chem. 2008; 283:22700-22708.

31. Moore JD, Staniszewska A, Shaw T, D'Alessandro J, Davis B, Surgenor A, Baker L, Matassova N, Murray J, Macias A, Brough P, Wood M, Mahon PC. VER-246608, a novel panisoform ATP competitive inhibitor of pyruvate dehydrogenase kinase, disrupts Warburg metabolism and induces contextdependent cytostasis in cancer cells. Oncotarget. 2014; 5:12862-12876. doi: 10.18632/oncotarget.2656.

32. Baggetto LG. Deviant energetic metabolism of glycolytic cancer cells. Biochimie. 1992; 74:959-974.

33. Schroeder S, Pendl T, Zimmermann A, Eisenberg T, Carmona-Gutierrez D, Ruckenstuhl C, Mariño G, Pietrocola F, Harger A, Magnes C, Sinner F, Pieber TR, Dengjel J, et al. Acetyl-coenzyme A: a metabolic master regulator of autophagy and longevity. Autophagy. 2014; 10:1335-1337.
34. Rambold AS, Cohen S, Lippincott-Schwartz J. Fatty acid trafficking in starved cells: regulation by lipid droplet lipolysis, autophagy, and mitochondrial fusion dynamics. Dev Cell. 2015; 32:678-692.

35. Gimm T, Wiese M, Teschemacher B, Deggerich A, Schödel J, Knaup KX, Hackenbeck T, Hellerbrand C, Amann K, Wiesener MS, Höning S, Eckardt KU, Warnecke C. Hypoxia-inducible protein 2 is a novel lipid droplet protein and a specific target gene of hypoxia-inducible factor-1. FASEB J. 2010; 24:4443-4458.

36. Rippo MR, Moretti S, Vescovi S, Tomasetti M, Orecchia S, Amici G, Catalano A, Procopio A. FLIP overexpression inhibits death receptor-induced apoptosis in malignant mesothelial cells. Oncogene. 2004; 23:7753-7760.

37. Dong LF, Swettenham E, Eliasson J, Wang XF, Gold M, Medunic Y, Stantic M, Low P, Prochazka L, Witting PK, Turanek J, Akporiaye ET, Ralph SJ, et al. Vitamin $\mathrm{E}$ analogs inhibit angiogenesis by selective apoptosis induction in proliferating endothelial cells: The role of oxidative stress. Cancer Res. 2007; 67:11906-119013. 